\title{
INFLUÊNCIA DE MÉTODOS DE SUPERAÇÃO DE DORMÊNCIA E DO ARMAZENAMENTO NA GERMINAÇÃO DE SEMENTES DE Senna macranthera (COLLADON) IRWIN \& BARNEBY (LEGUMINOSAE) ${ }^{1}$
}

\author{
ELIANE ROMANATO SANTARÉM² E MARIA ESTEFÂNIA ALVES AQUILA
}

Revista Brasileira de Sementes, vol. 17, $n^{0}$ 2, p. 205-209, 1995

\begin{abstract}
RESUMO - Grande parte das sementes de leguminosas apresentam dormência causada pela impermeabilidade do tegumento. O objetivo deste trabalho foi avaliar o processo germinativo de Senna macranthera. Sementes desta espécie foram submetidas a diferentes tratamentos de escarificação e amazenamento. Imersão em ácido sulfúrico concentrado por 5, 10 e 15min.; imersão em água quente por 5, 10 e 15min.; e escarificação mecânica, foram os meios utilizados para romper a barreira do tegumento de sementes armazenadas por 1 e 2 anos e sementes recém-coletadas. Com base nos resultados, foi observado que a escarificacão mecânica e a imersão em ácido sulfúrico concentrado quebraram a dormência tegumentar das sernentes favorecendo a germinação enquanto os tratamentos de imersão em água quente não foram eficientes. $\mathrm{O}$ armazenamento teve um efeito positivo na germinação quando associado aos tratamentos pré-germinativos.
\end{abstract}

Termos de indexação: dormência. escarificação, armazenamento, germinação, Sentia macranthera, Leguminosae

\section{INFLUENCE OF THE METHODS FOR SURPASSING DORMANCY AND STORAGE ON THE GERMINATION OF SEED OF Senna macranthera (COLLADON IRWIN \& BARNEBY (LEGUMINOSAE)}

\begin{abstract}
Seeds of leguminous species usually show dormanvy caused by impermeability of tegument. The objective of this work was to evaluate the germinative process in Senna macranthera. Seeds were submited to different treatments of scarification and storage. Immersion in concentrated sulfuric acid during 5, 10 and 15 minutes; immertion in boiling water for 5, 10 and 15 minutes and mechanical scaritication were the treatments used to break the tegument barrier of seeds stored for 1 and 2 years or freshly-harvested seeds. Results showed that the mechanical scaritication and the immertion in sulfuric acid had broken the tegumentar dormancy, improving the germination ratio, while treatments with boiling water were not efticient. The storage had a positive effect when associated to pregerminative treatments.
\end{abstract}

Index terms: dormancy, scarification, storage, germination, Senna macranthera, Leguminosae

\section{INTRODUÇÃO}

Muitas sementes têm sua germinação bloqueada pela barreira que os tegumentos impõem à sua embebição. Segundo Labouriau (1983), existe uma variedade de tratamentos pelos quais se elimina a impermeabilidade do tegumento como a escarificacão com lima, lixa ou outros instrumentos metálicos; aquecimento e fervura em água; pressões hidrostácas elevadas (até 2.000atm); vibrações de alta freqüência; ataque por ácido sulfúrico e lavagem em etanol. Nas leguminosas, a ocorrência de sementes

\footnotetext{
${ }^{1}$ Aceito para publicação em 30.06 .95

${ }^{2}$ UFRGS, Dep. de Botânica, Av. Paulo Gama, 40, Porto Alegre, RS
} 
dormentes devido à presença de tegumentos duros e impermeáveis à água é comum (Rolston, 1978; Carvalho \& Nakagawa, 1983).

Outro fato que influencia a porcentagem final de germinação nesta família é a temperatura (Bewley \& Blac, 1982). Brar et al. (1991) relataram que 18 das 20 espécies de leguminosas estudadas germinaram em temperaturas entre 10 e $30^{\circ} \mathrm{C}$.

Senna inacranthera (Colladon) Irwin \& Barneby var. nervosa (Vogel) é uma espécie nativa no Brasil, ocorrendo em diferentes ecossistemas (Bittencourt, 1981; Rizzini,1971). É de grande valor ornamental sobretudo para arborização urbana, pela beleza de sua flores (Rizzini \&Mors, 1976), tem um grande potencial econômico cmo fonte de tanino e de galactomanano, mas apresenta germinação desuniforme devido à impermeabildade do tegumento.

Visando preencher algumas das lacunas existentes no conhecimento sobre espécies nativas, em especial no que tange à fisiologia da germinação de $S$. macranthera, 0 objetivo deste trabalho foi verificar a influência da temperatura e o efeito de diferentes tipos de escarificação na germinação de sementes desta espécie, submetidas a diferentes períodos de armazenamento.

\section{MATERIAL E MÉTODOS}

O experimento foi conduzido no Laboratório de Fisiologia Vegetal do Departamento de Botânica da Universidade Federal do Rio Grande do Sul.

As sementes de Senna macranthera foram coletadas de uma única matriz em Porto Alegre e divididas em três grupos de acordo com o período de armazenamento: 2 anos, 1 ano e recém-coletadas. $O$ armazenamento foi feito em embalagem de papel e temperatura média de $20^{\circ} \mathrm{C}$.

Para avaliar o efeito da temperatura na germinação, sementes com 1 ano de armazenamento foram escarificadas mecanicamente e submetidas a testes sob temperaturas de 10,20 e $30^{\circ} \mathrm{C}$.

Para superar a dormência estrutural e verificar a influência do armazenamento nos métodos usados na superação da dormência, sementes - submetidas aos períodos de armazenamento descritos acima - foram aleatoriamente distribuídas nos seguintes tratamentos: sementes intactas (controle); imersão em ácido sulfúrico por 5, 10 e 15 minutos; imersão em água quente por 5, 10 e 15 minutos; escarificação mecânica. As sementes tratadas com ácido sulfúrico foram enxaguadas em água destilada a fim de eliminar os resíduos dessa substância. Nos tratamentos com água quente, a temperatura da água foi mantida a $90^{\circ} \mathrm{C}$, utilizando-se um banho-maria. A escarificação consistiu em um corte na testa da semente na região oposta ao eixo embrionário, o qual foi realizado com auxílio de um bisturi.

Em cada um dos tratamentos pré-germinativos, as sementes foram postas para germinar nas seguintes condições: placas gerbox $(15 \times 15 \mathrm{~cm})$ forradas com papel filtro umedecido com $30 \mathrm{ml}$ de água destilada, em 10 repetições de 20 sementes cada. Os experimentos foram mantidos em câmara de germinação sob as condições de $20 \pm 2^{\circ} \mathrm{C}$ e fotoperíodo de 10 horas. Previamente, testou-se a fotoblasticidade das sementes, constatando-se que a mesma é indiferente (dado não mostrado).

Acompanhou-se os experimentos em intervalos de 24 horas, durante 17 dias, usando-se como critério de germinação a emergência da radícula (Labouriau,1983).

A porcentagem final de germinação foi a média dos valores acumulados das 10 repetições. Para os testes estatísticos, os valores em porcentagem foram transformados em arco seno. Nos tratamentos de armazenamento $x$ escarificação, os dados foram submetidos à análise de variância de fatorial $2 \times 2$. O resultado final das sementes a expostas diferentes temperaturas foi analisado com base em um fator pelo ANOV A. O teste de Duncan foi utilizado para análise complementar $(=0,05)$. 


\section{RESULTADOS E DISCUSSÃO}

O efeito da temperatura sobre a germinação de sementes de leguminosas tem sido avaliado para várias espécies (Brar et al., 1991). A germinação de $S$. macranthera a $20^{\circ} \mathrm{C}$ iniciou no $3^{\circ}$ dia, enquanto que a $10^{\circ} \mathrm{C}$ teve início no $7^{\circ}$ dia, mas este atraso não afetou 0 percentual final de germinação (Figura 1). A temperatura de $30^{\circ} \mathrm{C}$ diminuiu a germinabilidade, apesar das sementes terem germinado a partir do $3^{\circ}$ dia (Figura 1). A partir deste resultado, foi escolhida a temperatura de $20^{\circ} \mathrm{C}$ para os demais experimentos. FIG. 1. Curvas de germinação de sementes de S. macranthera com 1 ano de armazenamento, submetidas a três regimes de temperatura. Letras diferentes indicam diferença significativa entre os tratamentos $(=0,05)$.

$\mathrm{Em} \mathrm{S}$. macranthera foi evidenciada a impermeabilidade do tegumento à água. $\mathrm{O}$ uso de escarificação mecânica e ácido sulfúrico concentrado têm sido apontados como os tratamentos pré-germinativos mais eficientes para romper a dormência estrutural em diferentes espécies (Rodrigues et al., 1990). Quando não foram utilizados pré-tratamentos germinativos, foi observada uma germinabilidade inferior a 1\% para sementes recém coletadas e com 1 ano de armazenamento (Tabela 1). Sementes armazenadas por 2 anos apresentaram um percentual de germinação $22 \%$, mostrando um desgaste no tegumento provocado pela dessecação. Independente do tempo de armazenamento empregado, sementes escarificadas mecanicamente atingiram a germinabilidade superior a 80\% (Tabela 1), confirmando resultados descritos de que esta técnica é eficiente na quebra da dormência estrutural.

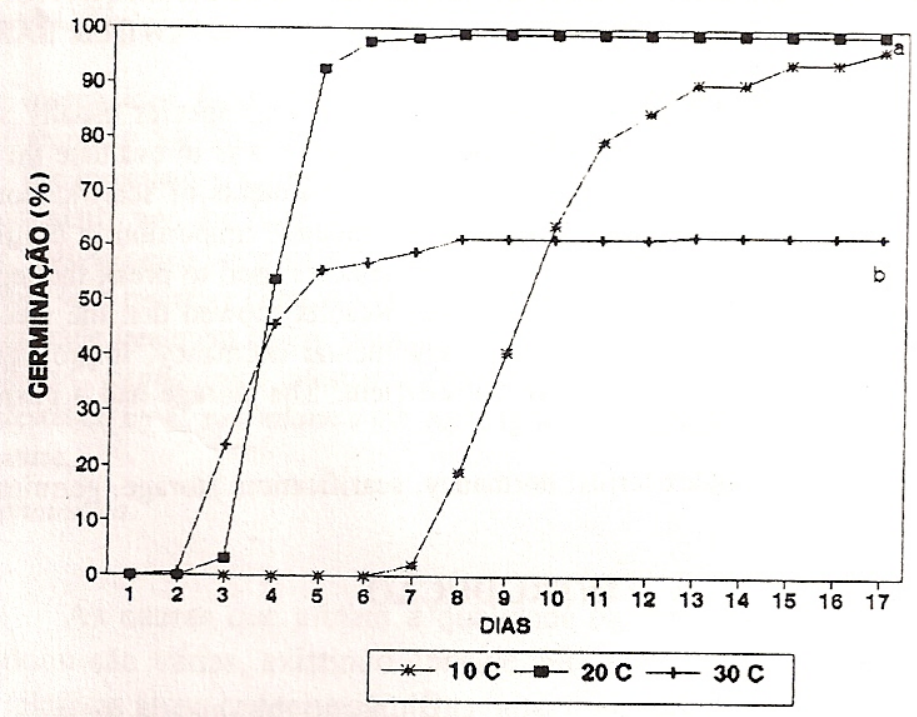

FIG. 1. Curvas de germinação de sementes de $S$. macranthera com 1 ano de armazenamento submetidas a três regimes de temperatura. Letras diferentes indicam diferença significativa entre os tratamentos $(=0,05)$. 
TABELA 1. Germinabilidade de sementes de S. macranthera submetidas a 3 tempos de armazenamento e a 8 tratamentos de escarificação.

\begin{tabular}{lccc}
\hline \multirow{2}{*}{ Tratamentos } & \multicolumn{3}{c}{ Armazenamento (anos) } \\
\cline { 2 - 4 } & 0 & 1 & 2 \\
\hline Controle & $1 \mathrm{~b}$ & $0 \mathrm{~b}$ & $22 \mathrm{a}$ \\
Água quente $5 \mathrm{~min}$ & $0 \mathrm{~b}$ & $28 \mathrm{a}$ & $36 \mathrm{a}$ \\
Água quente $10 \mathrm{~min}$ & $0 \mathrm{~b}$ & $0 \mathrm{~b}$ & $40 \mathrm{a}$ \\
Água quente $15 \mathrm{~min}$ & $0 \mathrm{c}$ & $10 \mathrm{~b}$ & $45 \mathrm{a}$ \\
Ácido sulfúrico $5 \mathrm{~min}$ & $27 \mathrm{~b}$ & $8 \mathrm{c}$ & $42 \mathrm{a}$ \\
Ácido sulfúrico10 min & $33 \mathrm{c}$ & $47 \mathrm{~b}$ & $76 \mathrm{a}$ \\
Ácido sulfúrico 15 min & $92 \mathrm{a}$ & $92 \mathrm{a}$ & $91 \mathrm{a}$ \\
Escarificação mecânica & $99 \mathrm{a}$ & $99 \mathrm{a}$ & $84 \mathrm{~b}$ \\
\hline
\end{tabular}

Letras diferentes indicam diferença significativa entre os tempos de estocagem (colunas). Teste Ducan $=0,05$. Germinabilidade $=$ Porcentagem final de germinação acumulada (Labouriau, 1983).

Os tratamentos de escarificação com ácido sulfúrico promoveram a germinação, sendo 15 min. o tempo de imersão mais eficiente (Figura 2). O período de armazenamento das sementes influenciou os tratamentos de 5 e 10 min. de imersão, sendo que sementes armazenadas por 2 anos foram mais sensíveis à ação do ácido (Tabela 1). Em diferentes espécies de Cassia, o ácido sulfúrico foi utilizado para romper a barreira do tegumento (Rodrigues et al., 1990; Al-Helal et al., 1989). Em Copaifera langsdorfii, a germinação ocorreu mais rapidamente em sementes imersas em ácido sulfúrico por 10 e 20 min. (Perez \& Prado, 1993), assim como em Leucaena leucocephala (Aquila \& Fett Neto, 1988). Há divergência de opiniões sobre quais camadas do tegumento são responsáveis pela impermeabilidade à água. Na sua revisão, Rolston (1978) aponta como barreira à entrada de água na semente a presença de ceras e compostos graxos na superfície ou a camadas de células abaixo da cutícula, os macroesclereídeos. A ação do ácido sulfúrico no amolecimento do tegumento da semente parece ser resultado da remoção da cutícula e exposição das camadas de macroesclerídeos.

A água fervente é um tratamento físico para quebrar a dormência de sementes de leguminosas. Apesar de ser um método vantajoso pelo baixo custo, os resultados obtidos com sua utilização têm sido contraditórios (Rodrigues et al., 1990). Em S. macranthera, os tratamentos com água quente foram menos eficientes do que aqueles com $\mathrm{H}_{2} \mathrm{SO}_{4}$ (Figuras 2 e 3), embora tenham promovido a germinação em sementes armazenadas por 2 anos (Tabela 1). As sementes recém coletadas não foram afetadas por este tratamento (Figura 3). Em Copaifera langsdorffii, os tratamentos imersão em água fervente por 5, $10 \mathrm{e}$ 15 min. inibiram a germinação (Perez \& Prado, 1993) e não foram eficientes para quebrar a dormência nas espécies de Cassia estudadas por Rodrigues et al. (1990).

De maneira geral, o armazenamento favoreceu a germinação e os maiores valores de germinabilidade final foram obtidos em sementes com 2 anos de estocagem (Tabela 1). Em experimentos com Mimosa bimucronata foi observado que, além da escarificação, a armazenagem por 1 ano favoreceu a germinação. Possivelmente, o armazenamento seria responsável por um aumento da permeabilidade do tegumento, diminuindo o número de sementes dormentes (Ferreira et al., 1992). 

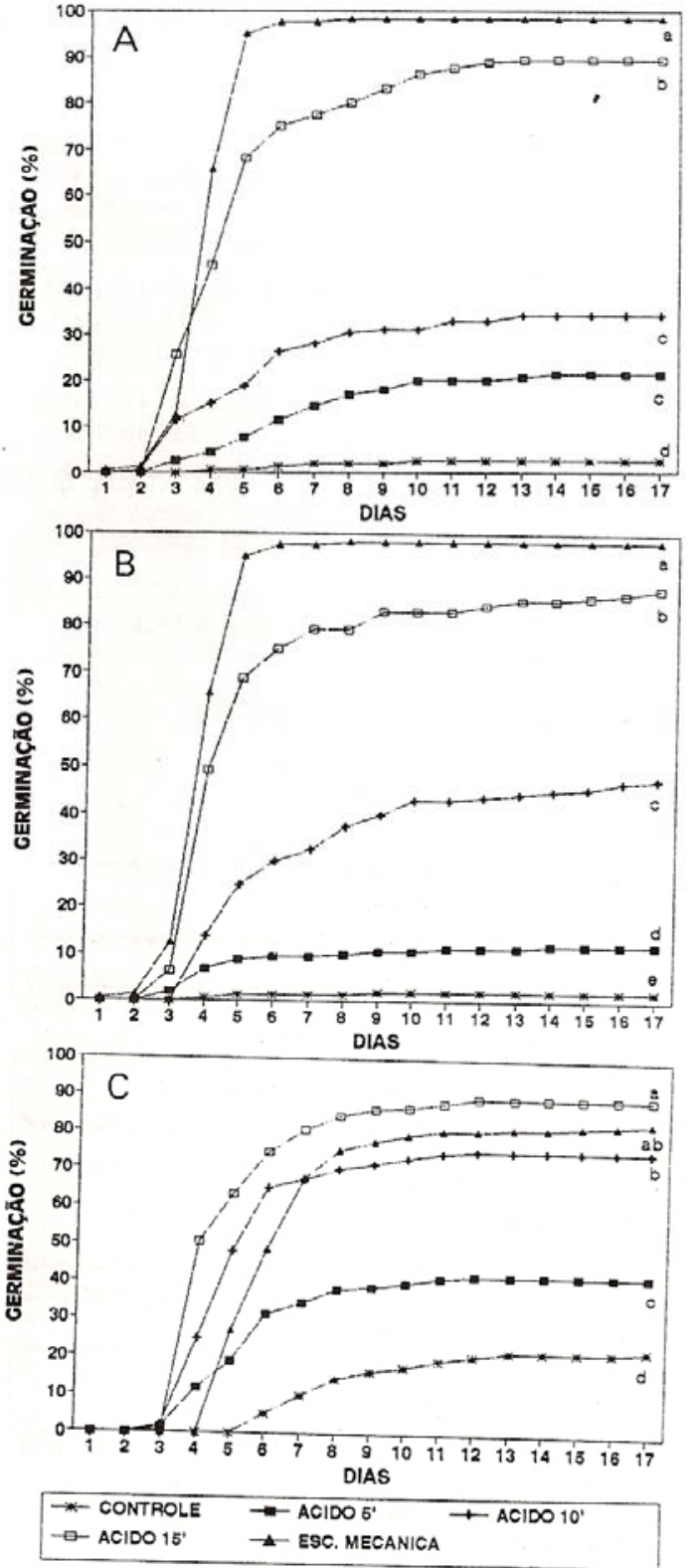

FIG. 2. Curvas de germinação de sementes de $S$. macranthera imersas em do ácido sulfúrico concentrado e escarificadas mecanicamente. (A) sementes recém coletadas, (B) sementes armazenadas por 1 ano e (C) sementes armazenadas por 2 anos. Letras diferentes indicam diferença significativa entre os tratamentos $(=0,05)$.
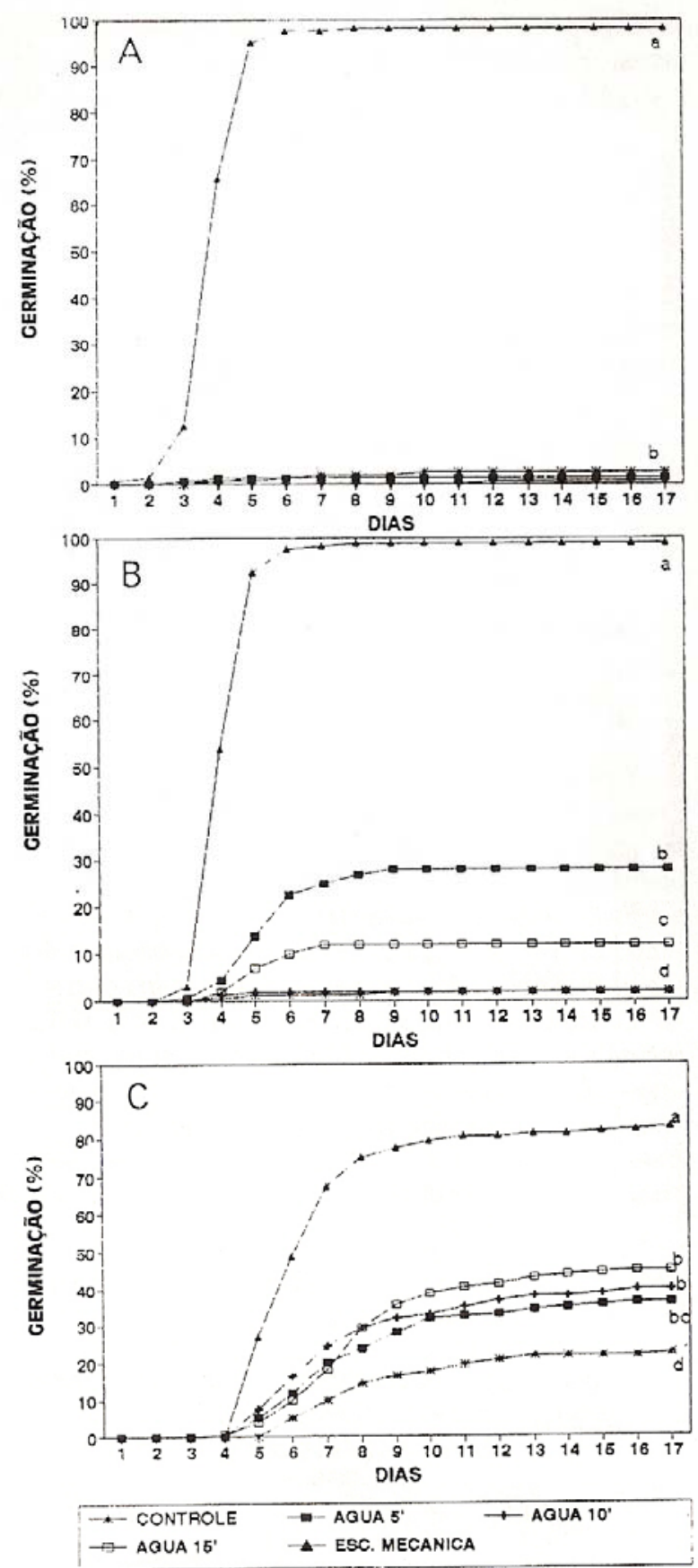

FIG. 3. Curvas de germinação de sementes de $S$. macranthera imersas em água quente $\left(90^{\circ} \mathrm{C}\right)$. (A) sementes recém coletadas, (B) sementes armazenadas por 1 ano, (C) sementes armazenadas por 2 anos. Letras diferentes indicam diferença significativa entre os tratamentos $(=0,05)$.

\section{CONCLUSÕES}

- Sementes de Senna macranthera apresentam dormência causada pela impermeabilidade do tegumento.

- Tratamentos pré-germinativos como escarificação mecânica e imersão em ácido sulfúrico concentrado por 15 min. foram os mais eficientes na quebra da dormência.

- O armazenamento por 2 anos, associado aos tratamentos pré-germinativos, favoreceu a germinação. 


\section{AGRADECIMENTOS}

Os autores agradecem a Diane I. Fiamoncini pela colaboração na realização deste trabalho e ao CNPq pelo financiamento do projeto.

\section{REFERÊNCIAS}

AL-HELAL, A.A; AL-FARRAJ, M.M.; EL-DESOKI, R.A \& AL-HABASHI, I. Germinatian resourse of Cassia senna L. seeds to sodium salts and temperature. J. Univ., Kuwait, 16:281-287, 1989.

AQUILA, M.E.A. \& FETT NETO, A.G. Influência dos processos de escarificação na germinação e crescimento inicial de Leucaena leucocephala (Lam.) de Wit. Rev. Bras. Sem., 10(1):73-86, 1988.

BEWLEY, J.D. \& BLACK, M. Physiology and biochemistry of seeds in relation to germination. Berlim: SpringVerlag,1982. v.2, 374p.

BITTENCOURT, H.F.R. Ecologia da polarização de Cassia macranthera. Rio de Janeiro: UFRJ, 1981 (Dissertação Mestrado).

BRAR, G.S; GOMES, J.F.; McMICHAEL, B.L.; MATCHES, A.G. \& TAYLOR, H.M. Germination of twenty forage legumes as influenced by temperature. Agron. J., 83(1):173-175, 1991.

CARVALHO, N.M. \& NAKAGAWA, J. Sementes: ciência, tecnologia e produção. Campinas: Fundação Cargil, 1983. 429p.

FERREIRA, A.G.; LIPP JOK, H. \& HEUSER, E.D. Efeitos da escarificação sobre a germinação e do pH sobre o crescimento de Acacia bonariensis Gill e Mimosa bimucronata (DC) OK. Rev. Bras. Fisiol. Veg., 4(1):63-65, 1992.

LABOURIAU, L.F.G. A germinação de sementes. Washington: Sec. Org. dos Estados Unidos, 1983. 174p.

PEREZ, S.C.J.G. de A. \& PRADO, C.H.B. de A. Efeitos de diferentes tratamentos prégerminativos e da concentração de alumínio no processo germinativo de sementes de Copaifera langsdorfii Desf. Rev. Bras. Sem., 15(1):115-118, 1993.

RIZZINI, C.T. A flora do cerrado (análise florística das savanas). In: FERRI, M.G. (org). Simpósio sobre o cerrado. São Paulo: Edgar Blücher/EDUSP. 1971.

RIZZINI, C.T. \& MORS, W.B. Botânica econômica brasileira. São Paulo: EDUSP, 1976. 207p.

RODRIGUES, E.H. de A.; AGUIAR, I.B. \& SADER, R. Quebra de dormência de sementes de 3 espécies do gênero Cassia. Rev. Bras. Sem., 12(2):17-27,1990.

ROLSTON, M.P. Water impermeable seed dormancy. The Botanical Review, 40(3):365396, 1978. 